\title{
ADAPTATION OF POTATO LATE BLIGHT PREDICTION MODELS FOR NEW ZEALAND
}

\author{
W.R. HENSHALL and R.M. BERESFORD \\ HortResearch, Mt Albert Research Centre, PB 92169, Auckland \\ Corresponding author: whenshall@hortresearch.co.nz
}

\begin{abstract}
Current management of potato late blight (caused by Phytophthora infestans) in the Pukekohe district is by frequent application of fungicides, but consumer concerns over chemical use may require more accurate targeting of spray applications to times of greatest disease risk. Decision support systems incorporating potato late blight infection models have the potential to assist growers in modifying management practices. Outputs of two overseas models and one developed locally were compared, using data from two weather stations, at Pukekohe (severe late blight area) and Lincoln (low disease risk), over the 2003/04 growing season. Two of the models were too sensitive for Pukekohe conditions, but the Smith model, developed in the United Kingdom, gave usable results. No attempt was made to verify the performance of the models under field conditions.
\end{abstract}

Keywords: Potato late blight, disease prediction model, fungicide, consumer.

\section{INTRODUCTION}

Despite a century of research, potato late blight (caused by Phytophthora infestans) remains a constant threat to potato production in many parts of the world. In high rainfall growing areas, such as Pukekohe (Franklin District, North Island, New Zealand), control of late blight is by frequent application of fungicides, but consumer concerns over chemical residues may force modifications to current practice.

Numerous late blight prediction models exist based on recognition of weather conditions suitable for infection, and use of these "infection periods" to produce risk warnings and spray recommendations. Once incorporated into decision support systems, the models have the potential to target fungicide application to times of greatest need, aiming to reduce and verifiably justify chemical use. However, the models are often complex to implement and require frequent access to weather data. From a farm management viewpoint, a regular spray schedule is much more easily implemented than one requiring action at short notice, particularly where growers are managing several properties.

The aim of this study was to examine two models developed overseas and one developed locally, to investigate differences in their patterns of predicted disease risk, and to simplify them for incorporation into a decision support system for disease management in potato crops. The overseas models of Smith (1956) and Fry et al. (1983) are based on temperature and number of hours of high relative humidity (RH). The third model (Hartill \& Young 1985), developed from field observations at Pukekohe in the early 1980 s, is based on temperature and surface wetness rather than RH. In their original forms the three models produce different outputs that make comparison difficult. For example, the Fry model is intended to be run in conjunction with a spray programme, and calculations restart after each application. For this study a daily risk value was required, independent of any management factors.

In the Pukekohe climate, where conditions are very conducive for late blight, both the Hartill-Young model and the Fry model are so sensitive that they can suggest the need for more fungicide applications than occur in a standard calendar-based schedule. To be 
useful, recommendations from any model must result in reduced fungicide applications compared to current practice. Because of over-sensitivity and the need to produce comparable results, the Fry and Hartill-Young models required modification.

\section{METHODS}

Infection periods (IPs) for each model were calculated from hourly temperature, $\mathrm{RH}$, and simulated leaf wetness obtained from HortResearch field weather stations at Pukekohe and at Lincoln (Canterbury, South Island, New Zealand). The Smith model requires two consecutive days with minimum temperature $10^{\circ} \mathrm{C}$ or above, and eleven or more hours per day with $\mathrm{RH} \geq 90 \%$. The Fry model, expressed as blight units, is also based on temperature and number of hours of high $\mathrm{RH}$, according to a complex table that takes cultivar susceptibility into account. In the current study criteria for a moderately susceptible cultivar were used. For the Hartill-Young model, if the output of an artificial leaf wetness sensor is above a threshold, then temperatures above a $7.2^{\circ} \mathrm{C}$ base are summed. A sum of 80 degree hours is one IP; IPs can follow successively under warm wet conditions. A $2 \mathrm{~h}$ gap in wetness is permitted under conditions of intermittent wetting and drying.

The output of the Smith model can be represented simply by a zero on each day that the model criteria are not met and a one on days when the criteria are fulfilled. To reduce the sensitivity of the Hartill-Young model and to simplify the output for comparison purposes, the first IP (if any) per day was ignored, and the remaining IPs per day normalised by dividing by the maximum number of IPs per day (three) to produce a number between zero and one. Fry blight units were simplified by ignoring the first five units per day. The modified sequences of daily Hartill-Young IPs and Fry blight units were then compared with the sequence of daily Smith IPs.

\section{RESULTS}

After modification, all three models produced the same basic pattern of normalised and reduced IPs, related to general weather conditions over the 2003/04 season at Pukekohe (Fig. 1), and at Lincoln (Fig. 2). The first half of the season at Pukekohe was relatively free of IPs, in contrast to the second half when conditions were often conducive to potato late blight, culminating in an exceptionally wet February 2004. The relative frequency of IPs detected by the three models was in the order Fry $>$ Smith $>$ HartillYoung (Table 1). There were far fewer IPs recorded by all three models at Lincoln, generally confined to February and March 2004, reflecting a climate that is less conducive to potato late blight than at Pukekohe.

TABLE 1: Numbers of days when potato late blight infection periods were predicted by three models at Pukekohe and Lincoln during 2003/04. Values shown are the total numbers for each model and the numbers detected by one model, two models and by all three models.

\begin{tabular}{lrrrrrrr}
\hline & \multicolumn{3}{c}{ Pukekohe } & & \multicolumn{3}{c}{ Lincoln } \\
\cline { 2 - 4 } \cline { 6 - 8 } & Smith & Fry & Hrtl-Yng & & Smith & Fry & Hrtl-Yng \\
\hline Smith & 12 & & & & 0 & & \\
Fry & 26 & 21 & & & 5 & 4 & \\
Hrtl-Yng & 5 & 2 & 5 & & 0 & 0 & 1 \\
All 3 & 10 & 10 & 10 & & 2 & 2 & 2 \\
\hline Total for each model & 53 & 59 & 22 & 7 & 11 & 3 \\
\hline
\end{tabular}


Although the general pattern of IPs was the same for all three models, closer examination shows the sequences did not often coincide within any one day. Table 1 details the number of occurrences when all three models detected an IP on the same day, when the three possible pairings occurred and when each model was the only one recognising an IP on that day. There was better agreement between the two overseas models than there was between the locally developed Hartill-Young model and the overseas models.
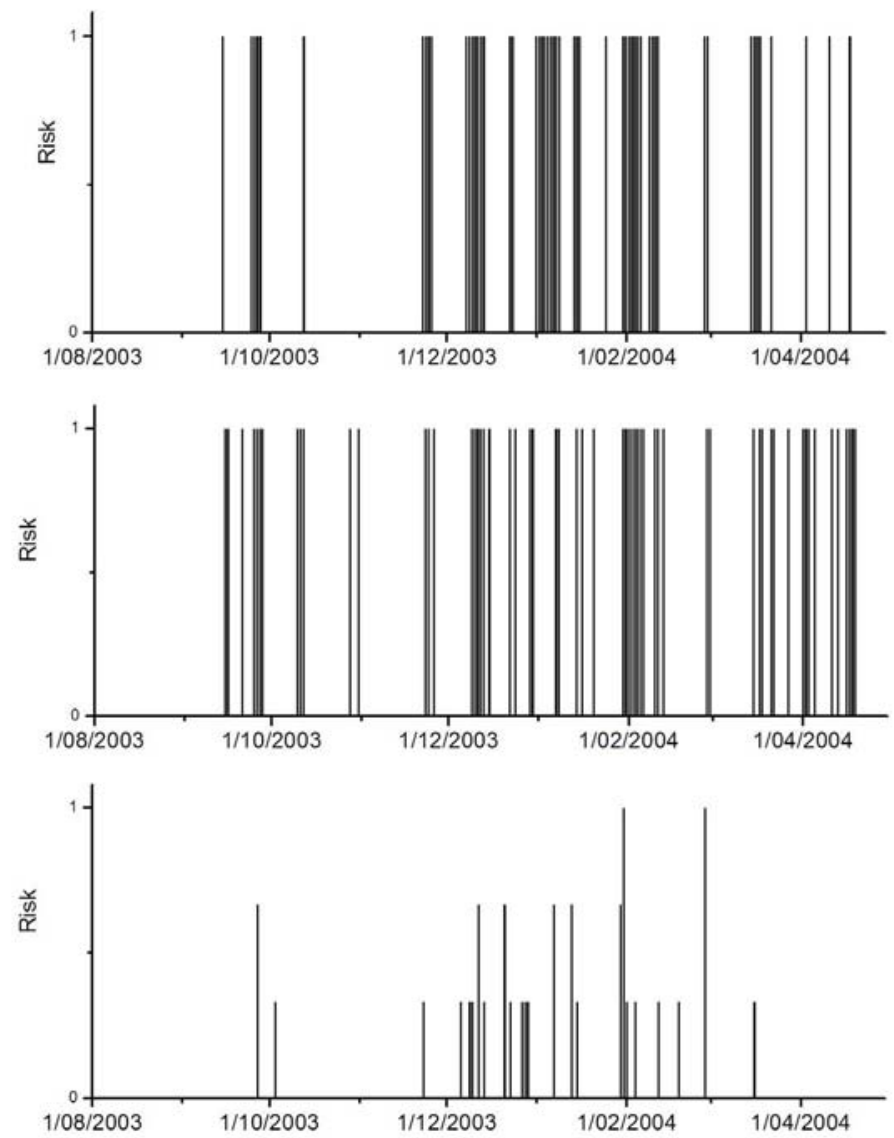

FIGURE 1: Infection periods calculated for the Smith model (top), the Fry model (centre) and the Hartill-Young model (bottom) using data from the HortResearch Pukekohe weather station over the 2003/04 growing season. The outputs of the Fry and Hartill-Young models have been modified as described in the text. 

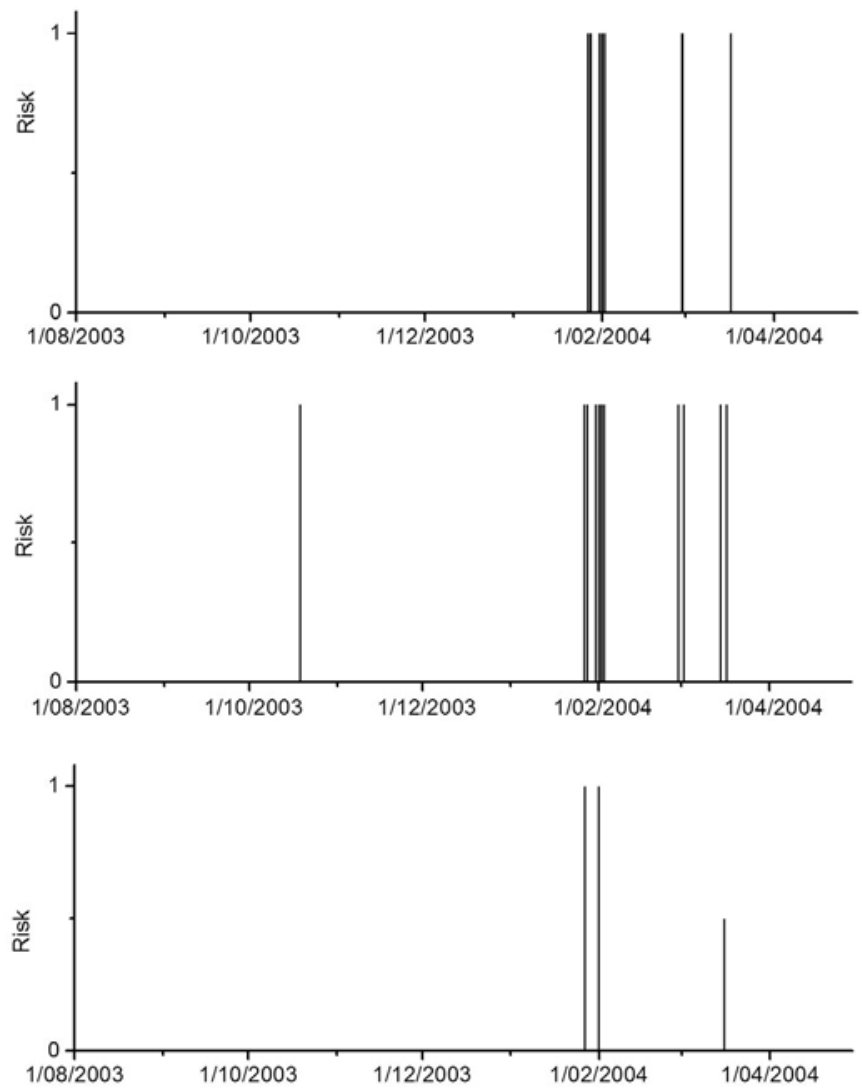

FIGURE 2: Infection periods calculated for the Smith model (top), the Fry model (centre) and the Hartill-Young model (bottom) using data from the HortResearch Lincoln University weather station over the 2003/04 growing season. The outputs of the Fry and Hartill-Young models have been modified as described in the text.

\section{DISCUSSION}

Firstly, it must be emphasised that no attempt has been made to verify the performance of any of the models under field conditions. On the assumption that all three models predict real infection risk, then the Smith model has the attraction of being simple and of discriminating well between different conditions. Once the background "noise" of frequent initial Hartill-Young IPs was removed, the remaining Hartill-Young IPs also gave good discrimination.

In the Pukekohe climate, Fry blight units were generated in abundance, as many as six per day. Fungicide treatment is recommended on accumulation of 35 blight units for moderately susceptible cultivars. This would equate to fungicide applications at 6-day intervals at times during the 2003/04 season. The Fry model therefore appears to be too 
sensitive for use in this district in the sense that more fungicide applications could be recommended than for a regular 7-day schedule. However, modified Fry blight units, as illustrated in Figs $1 \&$ 2, gave a similar pattern to Smith IPs.

The differences in timing illustrated by Table 1 can be partly explained by the fact that the Smith model requires 2 days before an IP is recognised. The other two models, even in modified form, are capable of recognising conditions favourable to late blight development within 1 day, and consequently recording the same event a day earlier than the Smith model.

Typically, disease prediction models become incorporated into decision support systems for growers. There have been numerous models developed for potato late blight. The University of California at Davis website lists 16 (University of California 2004), many of which are currently in common use in different areas of the world. Using models to forecast the timing of initial fungicide application appears adequate, but their use for scheduling applications throughout the growing season has been less successful (Gudmestad 1997). In the absence of field verification, the perceived over-sensitivity of the Fry model, and to a lesser extent the Hartill-Young model, is relative. It may be that potato late blight risk is indeed high for extended periods at Pukekohe, but it is the pattern of disease risk as much as the absolute risk that will be important for scheduling fungicide applications using a decision support system.

There is currently some concern internationally over the apparent low level of uptake of horticultural and agricultural decision support systems for disease management. One factor identified (Parker \& Campion 1997) is a perceived lack of cost benefit to the grower. Reduction in the number of fungicide applications in order to satisfy customer requirements may well result in increased disease levels, with corresponding yield loss, no matter how well-timed the applications may be. Savings on fungicide could be much less than increased harvesting and grading costs. Continued viability of potato exports may therefore depend on higher prices to offset the increased costs and possible yield reductions resulting from attempts to meet market demands for reduced pesticide use.

The aim of the present study was to select a model that reliably gave usable results, avoiding gross overprediction, and that was suitable for incorporation in a decision support system for potato crop and disease management. The Smith model appears to fulfil these requirements. In their original forms, the Fry and Hartill-Young models were too sensitive, but with some modification they gave similar outputs to the Smith model.

\section{ACKNOWLEDGEMENTS}

The authors thank Mike Gordon and Shane Smith of Pukekohe Growers Supplies Ltd for discussions on industry requirements for potato disease prediction models.

\section{REFERENCES}

Fry, W.E.; Apple, A.E.; Bruhn, J.A. 1983: Evaluation of potato late blight forecasts modified to incorporate host resistance and fungicide weathering. Phytopath. 73: 1054-1059.

Gudmestad, N.C. 1997: Forecasting late blight and fungicide application technology. www.apsnet.org/online/lateblite/papers/lb005.htm (30/04/04).

Hartill, W.F.T; Young K. 1985: Recent New Zealand studies on the chemical control of late blight of potatoes. In: Hill, G.D.; Wratt, G.S. ed. Potato growing - a changing scene. Agronomy Society of New Zealand. Pp. 55-60.

Parker, C.G.; Campion, S. 1997: Improving the uptake of decision support systems in agriculture. First European conference for information technology in agriculture. Copenhagen, Denmark. Pp. 129-134.

Smith, L.P. 1956: Potato late blight forecasting by $90 \%$ humidity criteria. Plant Path. 5 : 83-87.

University of California 2004: California PestCast disease model database. axp.ipm.ucdavis.edu /disease/database/potatolateblight.html (30/04/04). 